\title{
A Cadaveric Study on Morphometric Features of Spleen and Splenomegaly with Accessory Spleen in Hilum
}

Khaleel N ${ }^{1}$, Abinet GM ${ }^{2}$, Angadi A V ${ }^{3}$, Muralidhar PS ${ }^{4}$, Shabiya $\mathrm{M}^{5}$, Shaik Hussain Saheb *6.

${ }^{1,2}$ Associate Professor, Assistant professor and \& HOD, Department of Anatomy College of Medicine and Health sciences, Arba Minch University, Arba Minch, Ethiopia.

${ }^{3}$ Professor \& HOD, Department of Anatomy, SSIMS \& RC, Davanagere, Karnataka, India.

${ }^{4}$ Associate Professor of Anatomy, GIMS, Gulbarga, Karnataka, India.

${ }^{5}$ Associate Professor, Kasukurthi Health Care Pvt Ltd, Bangalore, Karnataka, India.

${ }^{6}$ Associate Professor of Anatomy, SSIMS \& RC, Davanagere, Karnataka, India.

\section{ABSTRACT}

Background: Anatomical knowledge regarding the external morphology of the spleen is essential for surgical intervention and radiological diagnosis. Splenomegaly is defined as pathologic enlargement of the spleen measured by size or weight. A normal spleen has a craniocaudal length of no more than $12 \mathrm{~cm}$ and weighs less than $200 \mathrm{~g}$. It is surrounded by a thin capsule. The spleen is usually not palpable unless it is enlarged; therefore, a palpable spleen is almost always abnormal. At times the spleen may be difficult to palpate, but dullness to percussion during inspiration in the area of the lower left intercostal space in the left anterior axillary line suggests splenic enlargement. Massive splenomegaly, weight $>1000$ g usually occurs in lymphoma, myeloproliferative disorders, visceral leishmaniasis, and malaria.

Materials and Methods: This study was conducted in different medical institutions, to find morphometric features, spenomegaly in cadaver during routine anatomy dissection as part of curriculum, 100 cadavers were observed to find out splenomegaly.

Results: Out of 100 spleens studied, 81 cases wedge shaped spleen was the most common, followed by 12 tetrahedral shaped spleens and 7 oval shaped spleens. Average weight of the spleen was $175 \mathrm{~g}$. Average length of the spleen was $11.64 \mathrm{~cm}$, Average breadth of the spleen was $7.3 \mathrm{~cm}$ and average thickness of spleen was $3.6 \mathrm{~cm}$. Out of 100 cadavers observed only one cadaver observed with massive splenomegaly with one accessory spleen in hilum. The spleen weight was $875 \mathrm{gm}$, length was $18.15 \mathrm{~cm}$, width was $8.65 \mathrm{~cm}$, thickness was $5.75 \mathrm{~cm}$ and extended upto $7 \mathrm{rib}$ and it is easily palpable below the rib cage from lumbar aspect. The cadaver was male and age around 55 years.

Conclusion: The morphometric knowledge of spleen will helpful for surgeons and for understanding deceases related spleen. The knowledge of splenomegaly is important in finding splenic disorders and accessory spleen information helpful in understanding embryonic development of spleen.

KEY WORDS: Splenomegaly, Spleen, Hilum of Spleen, Accessory spleen.

Corresponding Author: Shaik Hussain Saheb, Associate Professor of Anatomy, SSIMS \& RC, Davanagere, Karnataka, India. Mobile-9242056660 E-Mail: anatomyshs@gmail.com

Access this Article online

\section{Quick Response code}

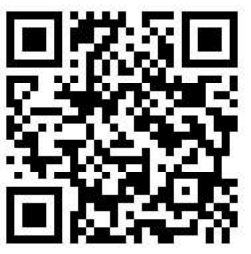

DOI: $10.16965 /$ ijar.2021.182

Journal Information

International Journal of Anatomy and Research

ISSN (E) 2321-4287 | ISSN (P) 2321-8967

https://www.ijmhr.org/ijar.htm

DOI-Prefix: https://dx.doi.org/10.16965/ijar

Article Information

Received: 12 Oct 2021

Peer Review: 13 Oct 2021

Revised: None
Accepted: 14 Nov 2021

Published (O): 05 Dec 2021

Published (P): 05 Dec 2021

\section{INTRODUCTION}

The spleen consists of a large encapsulated mass of vascular and lymphoid tissue. It is located in the left hypochondrium of abdomi- nal cavity. It is a graveyard of RBCs and also the storage site of platelets and blood. It filters the blood and protect the body against the infections. It is having two ends and two 
surfaces- anterior and posterior ends and diaphragmatic or superiolateral and visceral or inferiomedial surface. The anterior end is broad and faces laterally. The posterior end faces medially towards the vertebral column. The diaphragmatic surface is smooth and convex. It is covered by peritoneum and is related to abdominal surface of left dome of diaphragm which separate it from basal pleura, lower lobe of left lung and ninth to eleventh ribs. Its visceral surface is irregular and faces infer medially towards the abdominal cavity. It is having impressions for the left kidney, tail of pancreas, left colic flexures and fundus of stomach. The hilum of the spleen is located between the impressions of stomach and left kidney. The long axis of the hilum lies along the line of tenth rib. The spleen is connected to posterior abdominal fold via fold of peritoneum to kidney through lenorenal, to the colon with phrenosplenic ligament and to the anterolateral abdominal wall and stomach by the gastro splenic ligament $[1,2,3]$.

Splenomegaly indicating to an enlarged spleen. The spleen is located in the left hypocandric region and well protected by rib cage. Spleen functions includes in filtering blood by removing debris cells and helping the body fight infections. It is storage house for white blood cells and platelets. An enlarged spleen is characterized as one that is larger than $12 \mathrm{~cm}$ in length or over 400 grams in weight. Splenomegaly is considered a rare condition; it is due to usually occurs as a result of secondary causes. Infections associated with splenomegaly include viral infections, such as infectious mononucleosis, parasitic infections, such as malaria and leishmania, and bacterial infections. The excessive work of spleen due to infection can cause enlargement of the spleen. Leukemias, Portal hypertension, Liver cirrhosis, scarring also can cause spleen engorged with blood, leading to splenomegaly.

Spenomegaly is a serious condition upon trauma it can rupture spontaneously. It requires splenectomy. Splenomegaly causes abdominal discomfort, which might also be accompanied by localized pain near the spleen. Individuals with splenomegaly caused by cancer may experience night sweats and weight loss. Splenomegaly can usually be diagnosed through palpation during a physical exam and with help of MRI \& CT scan. Treatment of splenomegaly primarily focuses on treating the underlying cause. In certain cases, such as with massive splenomegaly caused by cancer, splenectomy, or the removal of the spleen, may be required $[4,5]$. The aim of present study is to find morphometric measurements of spleen and Splenomegaly in cadaver and measurements of it.

\section{MATERIALS AND METHODS}

This study was conducted in different medical institutions, to find the morphometric measurements of spleen, and to find splenomegaly in cadaver during routine anatomy dissection as part of curriculum, 100 cadavers were observed to find out splenomegaly. The cadaver was observed before starting of abdominal dissection. Abdominal palpation was done for finding enlargement of spleen. After finding the spleen with excessive enlargement, the spleen was collected and measured weight, length, width and thickness and observed for accessory spleen in its hilum. The findings were recorded.

\section{RESULTS}

Table 1: Presenting the measurements of spleen

\begin{tabular}{lc}
\hline Measurement of the spleen & \\
\hline Weight & $192 \mathrm{~g}$ \\
Length & $11.64 \mathrm{~cm}$ \\
Breadth & $7.3 \mathrm{~cm}$ \\
Thickness & $3.6 \mathrm{~cm}$ \\
\hline
\end{tabular}

Out of 100 cadavers observed in different medical colleges during routine anatomy dissection as part of curriculum. Out of 100 spleens studied, 81 cases wedge shaped spleen was the most common, followed by 12 tetrahedral shaped spleens and 7 oval shaped spleens. Average weight of the spleen was $192 \mathrm{~g}$. Average length of the spleen was $11.64 \mathrm{~cm}$, Average breadth of the spleen was $7.3 \mathrm{~cm}$ and average thickness of spleen was $3.6 \mathrm{~cm}$ (Table 1). Only one cadaver observed with massive splenomegaly with one accessory spleen in hilum. The spleen weight was $875 \mathrm{gm}$, length was $18.15 \mathrm{~cm}$, width was $8.65 \mathrm{~cm}$, thickness was $5.75 \mathrm{~cm}$ and extended upto $7 \mathrm{rib}$ 
and it is easily palpable below the rib cage from lumbar aspect (Figures 1,2,3). The cadaver was male and age around 55 years.

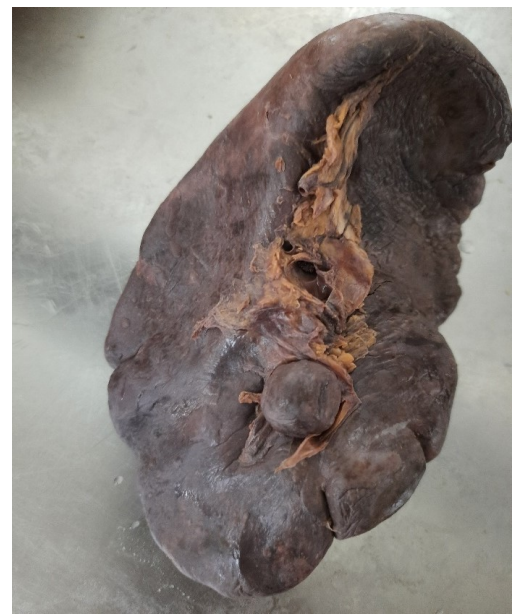

Fig. 1: Showing the spleen with excessive enlargement and accessory spleen in hilum

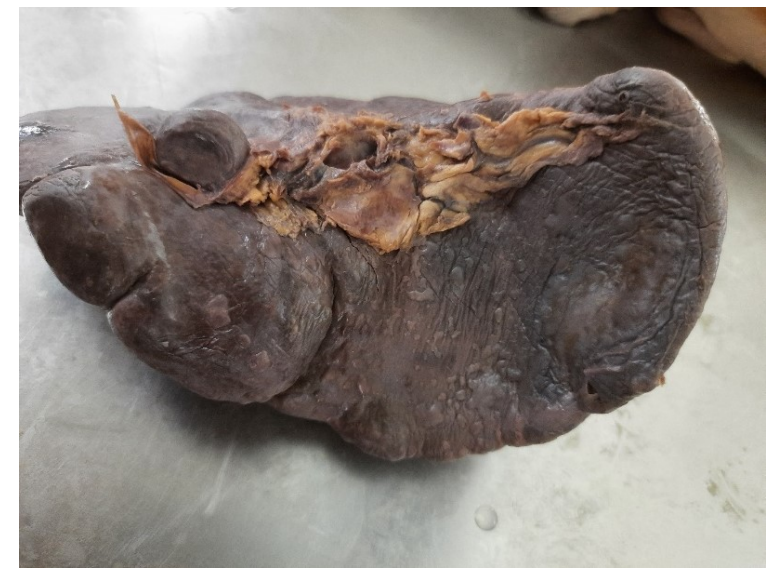

Fig. 2: Showing enlarged spleen, accessory spleen in hilum and impressive splenic notches.

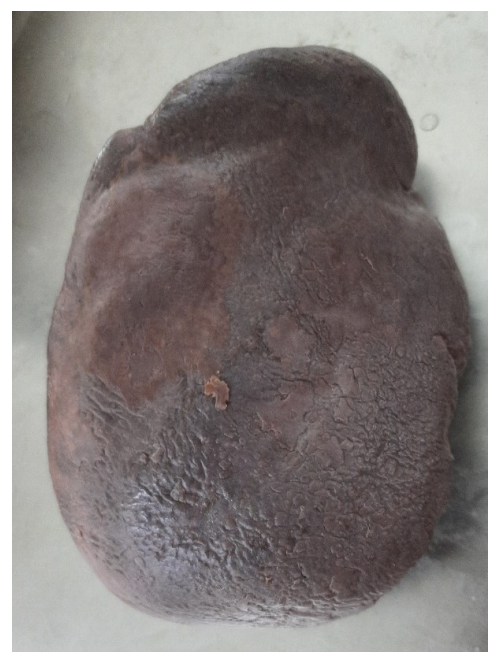

Fig. 3: Showing the diaphragmatic surface with costal impressions.

\section{DISCUSSION}

The spleen develops from both coelomic epithelium and from mesenchme of dorsal mesogastrium. During development several lobules form which fused with each other to form the spleen at later stage. In adult the notched superior border of spleen is a foot print of lobulated development of spleen in embryonic period $[6,7]$. The shape of the spleen varies from wedge, tetrahedral and oval, the shape of the spleen depends on neighbouring structures during development and fusion of multiple speniculi[1].

In the present study we have recorded different shapes of spleens that are wedge shaped $81 \%$, and it is most common, followed by tetrahedral $12 \%$ cases, and oval were $7 \%$ of spleens. The previous studies also reported about shapes of spleens but all were reported different values in relation with shapes. In the present study different dimensions of spleens were studied like length, width and thickness. The average length of the spleen was $11.64 \mathrm{~cm}$, average breadth of the spleen was $7.3 \mathrm{~cm}$ and average thickness of spleen was $3.6 \mathrm{~cm}$. In the present study average weight of the spleen was $195 \mathrm{~g}$. The value related to dimensions were in corelation with previous studies. The splenic notches were observed in most of the cases on superior border and near the anterior end $[7,8,9,10,11,12,13,14]$.

Splenomegaly is defined as enlargement of the spleen measured by weight or size. The spleen plays a significant role in hematopoiesis and immunosurveillance. The major functions of the spleen include clearance of senescent and abnormal erythrocytes. Approximately onethird of circulating platelets are stored in the spleen. The normal position of the spleen is within the peritoneal cavity in the left upper quadrant adjacent to ribs 9 through 11 . The normal-sized spleen abuts the stomach, colon, and left kidney. The size and weight of spleen may vary and correlates with weight, height, and sex of an individual, with larger spleen size seen in men compared to women, and in heavier or taller individuals. A normally sized spleen measures up to $12 \mathrm{~cm}$ in craniocaudal length. A length of $12 \mathrm{~cm}$ to $20 \mathrm{~cm}$ indicates splenomegaly, and a length greater than 20 $\mathrm{cm}$ is definitive of massive splenomegaly. The normal weight of the adult spleen is $70 \mathrm{~g}$ to $200 \mathrm{~g}$; a spleen weight of $400 \mathrm{~g}$ to $500 \mathrm{~g}$ indicates splenomegaly and spleen weight greater than $1000 \mathrm{~g}$ is definitive of massive 
splenomegaly. The normal-sized spleen is usually not palpable in adults. However, it may be palpable due to variations in body habitus and chest wall anatomy. Splenomegaly may be diagnosed clinically or radiographically using ultrasound, CT imaging, or MRI. Splenomegaly may be a transient condition due to acute illness or may be due to serious underlying acute or chronic pathology. In present study we have found one case with excessive enlargement of spleen, the spleen weight was $875 \mathrm{gm}$, length was $18.15 \mathrm{~cm}$, width was $8.65 \mathrm{~cm}$, thickness was $5.75 \mathrm{~cm}$ and extended upto 7 rib and it is easily palpable below the rib cage from lumbar aspect. The cadaver was male and age around 55 years. This values are in corelation with previous studies. $[15,16,17,18,19]$. The knowledge of the anatomy and function of the spleen is helpful for the understand of its role in disease. Studies on the morphometry of spleen will be helpful to surgeons and interventional radiologists.

\section{Conflicts of Interests: None}

\section{REFERENCES}

[1]. Rai G, Khanna S, Singh R, et al. Morphometric analysis of spleen in eastern up population - a cadaveric study J Evid Based Med Healthc 2020;7(33):1683-1687. DOI: 10.18410/jebmh/ $2020 / 351$.

[2]. Sinnatamby, Chummy S, and R J. Last. Last's Anatomy: Regional and Applied. Edinburgh: Churchill Livingstone, 2011;270 -272.

[3]. Standring S: Gray's Anatomy: The Anatomical Basis of the Clinical Practice, 39th edition. Edinburg: Elsevier Churchill Livingstone, 2006; 1239-44. https://www.osmosis.org/answers/splenomegaly/ 20/09/2021.

[4]. Ashwini Tangde, Bharat Sonwane, Rajan Bindu. A clinicohematological profile of splenomegaly. International Journal of Research in Medical Sciences. 2019;7(5):1934-1939.

[5]. Endo A, Ueno S, Yamada C and Takakuwa T. Morphogenesis of the spleen during the human embryonic period.Anat Rec (Hoboken). 2015; 298(5):820-6.
[6]. Rajashree B, Dharma Niranjan Mishra, Rajib Kanchan, Chinmayi Mohapatra. Morphometry of Human Cadaveric Spleen: An Institutional Study in the Population of Odisha. 2018;6(6):497-502.

[7]. Rao S, Katikireddi S. Morphometric study of human spleen. Int J Biol Med Res 2013;4:3464-8.

[8]. Brigden ML, Pattullo AL. Prevention and management of overwhelming post splenectomy infection: an update. Crit Care Med 1999;27:836-842.

[9]. Chaware PN, Belsare SM, Kulkarni YR, Sudhir Vishnupant, Ughade JM. The Morphological Variations. J ClinDiagn Res 2012;6:159-62.

[10]. Michels NA. The variational Anatomy of the spleen and the splenic artery. Am J Anat Anatomy. 1942;70:21-72.

[11]. Sangeeta M, Varalakshmi KL, Sahana BN. Cadaveric Study of Morphometry of Spleen. 2015:1(3);14-17.

[12]. Saheb H, Velichety SD, Haseena S. Morphological and Morphometric study of Human Foetal Spleen. Int J Anat Res. 2014; 2(1):234-38.

[13]. Gujar S et al. A cadaveric study of human spleen and its clinical significance. National Journal of Clinical Anatomy 2017;6(1):35-41.

[14]. Nigam Y, Knight J. The lymphatic system 2: structure and function of the lymphoid organs. Nursing Times [online]; 2020;116(11):44-48.

[15]. Nguyen Y, Stirnemann J, Belmatoug N. [Gaucher disease: A review]. Rev Med Interne. 2019 May;40(5):313-322.

[16]. Kang DW, Kim SH. Clinical aspects of splenomegaly as a possible predictive factor of coronary artery changes in Kawasaki disease. Cardiol Young. 2018 Dec 21;1-6.

[17]. P.P. Havaldar, S. Taz, S.H. Saheb Morphological study of obturator artery. Int J Anat Res, 2019;2:354-357.

[18]. Gala AR, Surapaneni T, Aziz N, Kallur SD. A Review of Outcomes in Pregnant Women with Portal Hypertension. J Obstet Gynaecol India. 2018 Dec;68(6):447-451.

[19].Jennifer Chapman; Pankaj Bansal; Amandeep Goyal; Alexandre M. Azevedo. Splenomegaly. Aug 2011. https://www.ncbi.nlm.nih.gov/books/ NBK430907.
How to cite this article: Khaleel N, Abinet GM, Angadi A V, Muralidhar PS, Shabiya M, Shaik Hussain Saheb. A Cadaveric Study on Morphometric Features of Spleen and Splenomegaly with Accessory Spleen in Hilum. Int J Anat Res 2021;9(4):8181-8184. DOI: 10.16965/ ijar.2021.182 